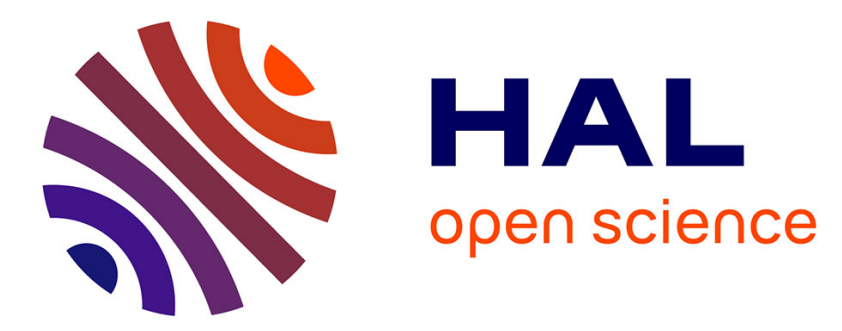

\title{
PEGylated PNiPAM Microgels: Synthesis, Characterization and Colloidal Stability
}

Julien Es Sayed, Cédric Lorthioir, Patrick Perrin, Nicolas Sanson

\section{To cite this version:}

Julien Es Sayed, Cédric Lorthioir, Patrick Perrin, Nicolas Sanson. PEGylated PNiPAM Microgels: Synthesis, Characterization and Colloidal Stability. Soft Matter, 2019, 15, pp.963-972. 10.1039/c8sm02156b . hal-01966786

\section{HAL Id: hal-01966786 \\ https://hal.science/hal-01966786}

Submitted on 29 Dec 2018

HAL is a multi-disciplinary open access archive for the deposit and dissemination of scientific research documents, whether they are published or not. The documents may come from teaching and research institutions in France or abroad, or from public or private research centers.
L'archive ouverte pluridisciplinaire HAL, est destinée au dépôt et à la diffusion de documents scientifiques de niveau recherche, publiés ou non, émanant des établissements d'enseignement et de recherche français ou étrangers, des laboratoires publics ou privés. 


\section{PEGylated PNiPAM Microgels : Synthesis,}

\section{Characterization and Colloidal Stability}

${ }^{\text {a }}$ Soft Matter Sciences and Engineering, ESPCI Paris, PSL University, Sorbonne Université, CNRS, F-75005 Paris.

6

7

8

9

10

11

12

13

14

15

16 


\section{ABSTRACT}

The challenge of this work is to synthesize highly stable thermoresponsive microgels that could be used in diverse applications. To achieve this, $N$-isopropylacrylamide (NiPAM) based microgels were first synthesized by surfactant-free precipitation polymerization of NiPAM in the presence of poly(ethylene glycol) methacrylate (PEG) as macro-comonomer and methylene-bis-acrylamide (MBA) as chemical crosslinker. By combining a complete set of techniques such as dynamic light scattering (DLS), scanning electron microscopy (SEM), zetametry, ${ }^{1} \mathrm{H}$ NMR and micro-differential scanning calorimetry ( $\left.\mu \mathrm{DSC}\right)$, we clearly demonstrate that (i) the incorporation of the PEG chains control the size and the polydispersity of the NiPAM-based microgels whereas the thermal behavior in solution (enthalpy, volume phase transition temperature, VPTT) remains almost the same as for pure NiPAM microgels (ii) the PEG chains are mainly located at the microgel periphery and (iii) the presence of the PEG chains strongly increases the colloidal stability of microgels in electrolyte solutions at high temperature. 
During the last three decades, nanogels/microgels have received considerable interest for applications in diverse domains notably in biomedical applications such as drug delivery, biosensors, targeted therapies, ${ }^{1-5} \ldots$ Microgels are defined as colloidal gel particles having diameters in the range from 0.05 to $1 \mu \mathrm{m}$ exhibiting network structure that swells in a suitable solvent. Research has been directed towards the synthesis of stimuli-responsive or "smart" microgels, which properties can be modulated reversibly in response to an environmental stimulus such as $\mathrm{pH}$, temperature, and light to name but a few. ${ }^{6}$ Among the stimuli-responsive microgels, it is well etablished that thermoresponsive $N$-isopropylacrylamide (NiPAM) based microgels are the most used mainly due to both the polymerization process which allow to synthesize well-defined pure or functionalized particles and its volume phase transition temperature close to human body. ${ }^{7}$ However, while the microgel synthesis is now well described, the control of the colloidal stability of thermoresponsive microgels remains a key challenge for their use in the applications cited previously.

Generally, for a dispersion of pure NiPAM microgels, an increase of electrolyte concentration leads to (i) a decrease of the microgel size (ii) a shift of the VPTT towards lower temperatures and (iii) an aggregation at temperatures higher than the VPTT. ${ }^{8-10}$ One of the strategies to improve the colloidal stability of thermoresponsive microgels is to incorporate suitable comonomers such as charged ones at the periphery of the microgel network to maintain a sufficiently high hydrophilicity at high temperature, typically above the so-called Volume Phase Transition Temperature (VPTT). For instance, Farooqi et al. showed that microgels synthesized by copolymerizing NiPAM and different acrylic acid (AAc) contents are colloidally stable at $\mathrm{pH} 9$ up to $0.1 \mathrm{M}$ whatever the temperature. However, at $\mathrm{pH}$ values higher than the pKa of acrylic acid, the VPTT shifts towards high temperature until it disappears. ${ }^{11}$ Moreover, decreasing $\mathrm{pH}$ leads to poly(NiPAM-Co-AAc) microgels aggregation 
at temperatures above the microgel VPTT in pure water. In order to tackle the VPTT dependence of the poly(NiPAM-co-AAc) microgels towards $\mathrm{pH}$, Das et al. have incorporated sulfobetaine monomers into NiPAM-based microgels. Due to the high hydrophilicity of the zwitterionic monomers, the colloidal stability was maintained up to $1 \mathrm{M} \mathrm{NaCl}$ even at high temperatures. However, the incorporation of zwitterionic monomers into the microgel leads to an increase of the microgel size as well as a shift of the VPTT towards high temperature. ${ }^{12}$ The colloidal stability of thermoresponsive NiPAM microgels can also be improved by incorporation of poly(ethylene glycol) (PEG) chains, which are well known to shield the surface of polymeric colloids against aggregation. ${ }^{13}$ This concept was used by Gan et al., who first synthesized thermoresponsive microgels that efficiently resist protein adsorption-induced aggregation. The authors prepared PEGylated thermoresponsive microgels by surfactant precipitation polymerization by copolymerization of NiPAM with PEG macro-comonomers $\left(M_{\mathrm{w}}=1000 \mathrm{~g} / \mathrm{mol}\right) .{ }^{14}$ However, increasing PEG content (from 10 to $40 \mathrm{wt} \%$ ) leads to microgels with an increasing polydispersity with both a shift to higher temperature and a broadness of the VPTT. Similar observations were made recently by Trongsalitkul et al. for NiPAM microgels containing PEG chains with different number average molar masses $M_{\mathrm{n}}$ ranging from 300 to $1100 \mathrm{~g} / \mathrm{mol}^{15}$

In the light of the reports cited above, it appears challenging to synthesize thermoresponsive NiPAM-based microgels presenting a high colloidal stability without changing their solution properties. To tackle this problem, we synthesized thermoresponsive NiPAM-based microgels by surfactant-free precipitation copolymerization of NiPAM and poly(ethylene glycol) methacrylate. Compared to previous reported works, we investigated in the present work how to synthesize monodisperse PEGylated NiPAM-based microgels of different sizes with high colloidal stability in electrolyte solution without changing the microgel VPTT. 


\section{EXPERIMENTAL}

\section{Materials}

$N$-isopropylacrylamide (NiPAM) monomer, $N, N^{\prime}$-methylenebisacrylamide (MBA) and potassium persulfate (KPS) were purchased from Sigma-Aldrich and used as received. Poly(ethylene glycol) monomethacrylate (PEGMAOH) macromonomer with a weight average molar mass of $M_{\mathrm{w}}=2000 \mathrm{~g} / \mathrm{mol}$ was purchased from Polysciences. Ultrapure deionized water with a minimum resistivity of $18 \mathrm{M} \Omega . \mathrm{cm}$ (milliQ, Millipore, France) was used all experiments.

\section{Synthesis of Microgels}

All NiPAM-based microgels were synthesized by surfactant-free precipitation polymerization. ${ }^{16}$ In a typical synthesis, $3 \mathrm{~g}$ of NiPAM (26.5 mmol) were dissolved in $210 \mathrm{~mL}$ of water in a three-neck round-bottom flask equipped with a condenser under stirring (250 rpm) with a teflon semi-lunar shaped stirring blade at ambient temperature and under $\mathrm{N}_{2}$ flow. Pre-dissolved MBA in $40 \mathrm{~mL}$ of water ( $2 \mathrm{~mol} \%$ vs NiPAM monomer) and PEGMAOH in 40 $\mathrm{mL}$ of water (from 0 to $1 \mathrm{~mol} \%$ vs NiPAM monomer) were added to the reaction mixture.

111 The reaction medium was then heated to $67{ }^{\circ} \mathrm{C}$ and purged under $\mathrm{N}_{2}$ flow for 40 minutes.

112 Subsequently, KPS previously dissolved in $10 \mathrm{~mL}$ of water ( $2 \mathrm{~mol} \%$ vs NiPAM monomer), was injected in the reaction mixture and the reaction was allowed to progress for 4 hours under continuous stirring $(250 \mathrm{rpm})$ and $\mathrm{N}_{2}$ flow. Finally, the reaction media was exposed to 
Table 1 Chemical composition of PEGylated NiPAM microgels

\begin{tabular}{ccccccc}
\hline \multirow{2}{*}{ Microgels } & NiPAM & MBA & KPS & PEGMAOH & PEGMAOH $^{b}$ & PEGMAOH \\
\cline { 2 - 6 } & $\mathrm{n}(\mathrm{mmol})$ & $\mathrm{mol} \%$ & $\mathrm{~mol} \%$ & $\mathrm{~mol} \%$ & $\mathrm{~mol} \%$ & $\mathrm{wt} \%$ \\
\hline MG-0 & 26.5 & 2 & 2 & 0 & 0 & 0 \\
MG-0.1 & 26.5 & 2 & 2 & 0.1 & 0.09 & 1.3 \\
MG-0.25 & 26.5 & 2 & 2 & 0.25 & 0.18 & 3.2 \\
MG-0.5 & 26.5 & 2 & 2 & 0.5 & 0.36 & 6.0 \\
MG-1 & 26.5 & 2 & 2 & 1 & 0.74 & 11.7
\end{tabular}

$125{ }^{a}$ Feed ratio of PEG macromonomer to NiPAM monomer used in the microgel synthesis. ${ }^{\text {bc }}$ Molar and weight ratios of PEG macromonomer to NiPAM within the microgel, determined by ${ }^{1} \mathrm{H}$ NMR.

\section{Characterization}

${ }^{1} \boldsymbol{H}$ NMR. NMR experiments in deuterated DMSO were performed on a Bruker Avance III probe at $25^{\circ} \mathrm{C}$. 
${ }^{1} \mathrm{H}$ solution-state NMR measurements were conducted on a Bruker Avance 300 NMR spectrometer at a magnetic field of $7.0 \mathrm{~T}$, corresponding to a ${ }^{1} \mathrm{H}$ Larmor frequency of 300.1 MHz. Variable-temperature single-pulse experiments between 2 and $70{ }^{\circ} \mathrm{C}$ were performed using a $5 \mathrm{~mm}$ inverse ${ }^{1} \mathrm{H} /{ }^{13} \mathrm{C}$-selective probe and a BCU accessory, for the temperature range from 2 to $25^{\circ} \mathrm{C}$. The $90^{\circ}$ pulse length was set to $7.5 \mu$ s and the recycle delay was adjusted to at least 5 times the longest $\mathrm{T}_{1}\left({ }^{1} \mathrm{H}\right)$ relaxation time, i.e. between 30 and $90 \mathrm{~s}$, depending on the temperature value. The ${ }^{1} \mathrm{H}$ transverse relaxation signal was determined using the PROJECT pulse sequence (Periodic Refocusing Of $J$ Evolution by Coherence Transfer) ${ }^{17}$, with a value of the interpulse delay, $\tau$, set to $0.25 \mathrm{~ms}$. The measured relaxation functions were normalized by the amplitude of the ${ }^{1} \mathrm{H}$ magnetization following a single cycle of the PROJECT experiment (that is to say $\left[\tau-180^{\circ}-\tau-90^{\circ}-\tau-180^{\circ}-\tau\right]$ ).

The quantification of the concentration of EG and NiPAM repeat units as a function of temperature was obtained by means of a solution of maleic acid in $\mathrm{D}_{2} \mathrm{O}$, chosen as an external reference. A $5 \mathrm{~mm}$ tube with a coaxial insert (NI5CCI-B, Norell) filled by such a solution, prepared with an accurately-defined concentration $(22.1 \mathrm{mM})$, was systematically used for all the investigated microgel solutions. Prior to the experiments, a calibration of the temperature acid in $\mathrm{D}_{2} \mathrm{O}$. Following each temperature change and once the target value was achieved for at least $10 \mathrm{~s}$, a delay of $15 \mathrm{~min}$ was introduced in order to ensure the thermal equilibration of the sample. During the NMR measurements, the temperature was regulated within $\pm 1{ }^{\circ} \mathrm{C}$.

Dynamic light scattering (DLS). Dynamic light scattering was performed on an ALV goniometer (ALV/CGS-3) with a He/Ne laser operated at a wavelength of $\lambda=633 \mathrm{~nm}$, in combination with an ALV/LSE-5003 correlator. Prior to DLS measurements, all samples 
$157 \mathrm{C}_{\mathrm{MG}}=0.01 \mathrm{wt} \%$. The microgel solutions were equilibrated overnight at room temperature, and filtered through Nylon filters of $0.8 \mu \mathrm{m}$ pore size. In order to study the variation of the size of the microgel as a function of temperature, the samples were kept at rest within the apparatus at each temperature for 10 min prior to measurements. The results are given as intensity-averaged hydrodynamic diameters (mean diameters based on the intensity of the scattered light).

Scanning electron microscopy (SEM). Scanning electron microscopy observations were performed on a FEG Magellan 400 FEI Thermofisher microscope. The observation takes place at a high acceleration tension of $5 \mathrm{kV}$.

Micro-calorimetry ( $\mu D S C)$. The phase transition of NiPAM-based microgels in aqueous solution was investigated by Micro Differential Scanning Calorimetry using a micro DSC III instrument from SETARAM. The microgel solution $\left(\mathrm{C}_{\mathrm{MG}}=0.5 \mathrm{wt} \%\right)$ and the reference filled with the same quantity of solvent, were equilibrated and submitted to a temperature cycle between 10 and $50{ }^{\circ} \mathrm{C}$. Both heating and cooling rates were fixed at $0.1{ }^{\circ} \mathrm{C} / \mathrm{min}$.

Zeta-potential measurements. The zeta-potential $(\zeta)$ of the synthesized microgels was determined from 15 to $50{ }^{\circ} \mathrm{C}$ by a Zetasizer Nano-ZS90 from Malvern. Microgels were suspended in a $10^{-4} \mathrm{M} \mathrm{NaCl}$ water solution at a concentration of $\mathrm{C}_{\mathrm{MG}}=0.1 \mathrm{wt} \%$ and the solutions were left $10 \mathrm{~min}$ at each temperature prior to measurements.

\section{RESULTS AND DISCUSSION}

Several microgels were synthesized by surfactant free copolymerization of $\mathrm{N}$ isopropylacrylamide (NiPAM) as main monomer and different amounts of poly(ethylene glycol) monomethacrylate (PEGMAOH) as co-monomer from 0 to $1 \mathrm{~mol} \%$ corresponding to a maximum weight ratio of $11.7 \mathrm{wt} \%$ as reported in Table 1 . The chemical compositions of the NiPAM-based microgels have been investigated using ${ }^{1} \mathrm{H}$ NMR spectroscopy in 
deuterated DMSO-d 6 as shown in Figure 1. The amount of PEG macromonomer incorporated within the microgel was determined by comparing the peak areas assigned to the methylene protons of the PEG macro-comonomer $(3.5 \mathrm{ppm})$ and one related to the isopropyl group of NiPAM (3.8 ppm) (Figure 1a). Figure 1b shows the molar ratio of PEG macromonomer to NiPAM within the microgel as a function of the molar ratio of PEG macromonomer to

NiPAM introduced in the batch synthesis. The linear variation indicates that the molar ratio of PEG macromonomer to NiPAM units within all the synthesized microgels is equal to $74 \%$ irrespective of the feed molar ratio of PEG macromonomer to NiPAM. Knowing that the PEG macromonomer content introduced in the reaction medium is low, the value of the incorporation rate of PEG macromonomer into the microgel is in line with the theoretical 192 value according the reactivity ratios, $\mathrm{r}_{\mathrm{NiPAM}}=1.2$ and $\mathrm{r}_{\mathrm{PEGMAOH}}=0.13$ reported by Alava et al.. ${ }^{18}$ 193 In order to investigate the influence of PEG incorporation on the size, polydispersity, swelling ratio, volume phase transition temperature and transition enthalpy of NiPAM-based microgels, they were characterized by combining dynamic light scattering (DLS), scanning electron microscopy (SEM), proton NMR spectroscopy and microcalorimetry.

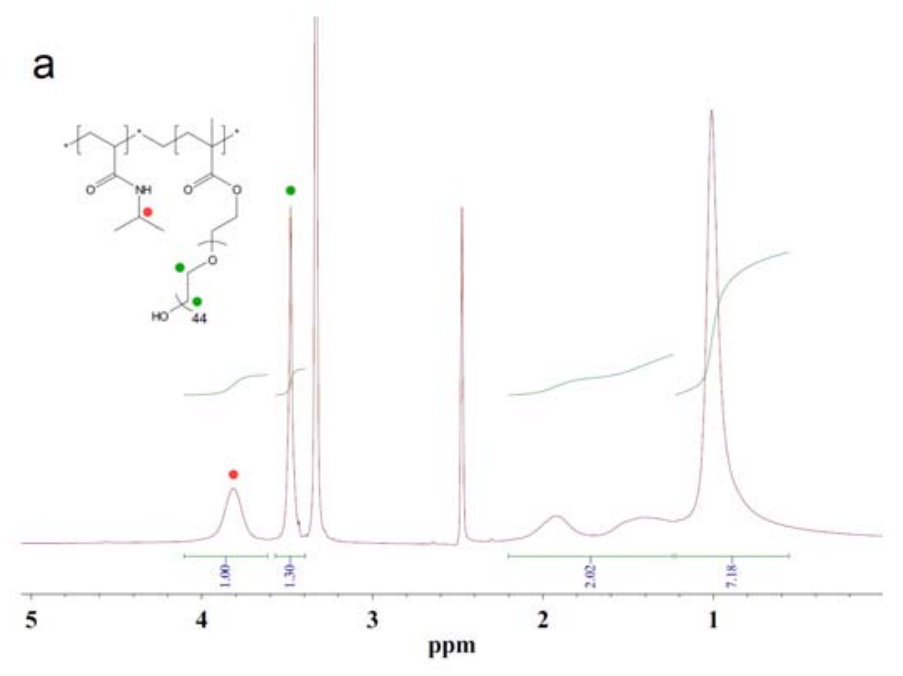




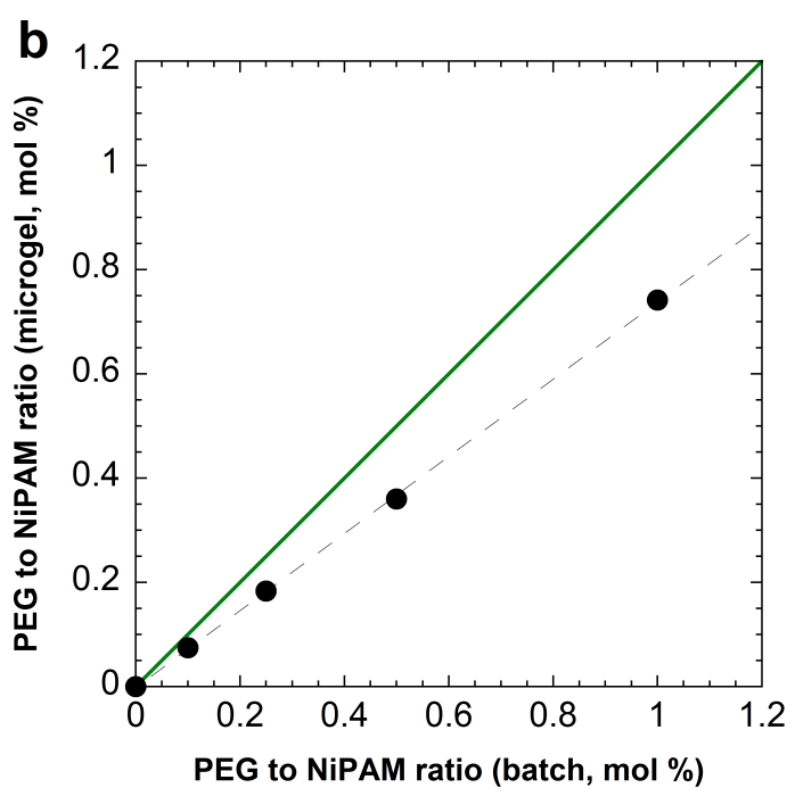

Fig. 1 (a) ${ }^{1} \mathrm{H}$ NMR spectrum of MG-1 in DMSO- $\mathrm{d}_{6}$ at $25{ }^{\circ} \mathrm{C}$ and corresponding chemical structure. (b) Efficiency of the PEG macromonomer incorporation in the NiPAM-based microgel. Correlation between the microgel composition (mol \%) and the batch synthesis ratio of PEG chains to NiPAM repeat units. The PEG to NiPAM molar ratios have been determined by ${ }^{1} \mathrm{H}$ NMR. The solid line (green) represents a theoretical $100 \%$ incorporation efficiency.

\section{Influence of PEG incorporation on the NiPAM phase separation process}

As NiPAM is the main component of the synthesized microgels, we first investigated their thermosensitive character using micro-calorimetry since the transition temperature as well as the transition enthalpy are coupled to the structure of the polymer chain (chemical composition, architecture) and to the environmental conditions (co-solvent, ionic strength). A typical thermogram carried out at a slow rate of $0.1{ }^{\circ} \mathrm{C} / \mathrm{min}$ in order to minimize the kinetic effects is given in Figure 2a for MG-1, the microgel with a PEG batch concentration of $1 \mathrm{~mol}$ $\%$ corresponding to $11.7 \mathrm{wt} \%$. The microgels exhibit a heating endothermic peak and cooling exothermic peak characteristic of the thermal phase transition of NiPAM polymer chains embedded into the microgel. This endothermic process observed during the heating scan is related to the overall energy balance of hydrogen bonds disruption/reformation between 
amide groups and water molecules. ${ }^{19}$ For the different microgels, both the thermal enthalpy, $\Delta \mathrm{H}$, expressed in $\mathrm{kJ}$ per mole of NiPAm and peak temperature, $\mathrm{T}_{\text {peak, }}$, respectively corresponding to the area under the thermogram and the temperature where the thermal capacity is the highest were plotted as a function of the PEG macromonomer to NiPAM monomer molar ratio (Figure 2b). Note that the obtained values were normalized by the real amount of NiPAM repeat units into the microgel determined by ${ }^{1} \mathrm{H}$ NMR spectroscopy. The pure NiPAM microgels, MG- 0 , shows the highest enthalpy with a value of $\Delta \mathrm{H}=5.3 \mathrm{~kJ} / \mathrm{mol}$ consistent with reported studies. ${ }^{20,21}$ The enthalpy of NiPAM-based microgels, in which PEG macromonomers have been incorporated, decreases with increasing the PEG macromonomer content from $4.9 \mathrm{~kJ} / \mathrm{mol}$ for MG- 0.25 to $4 \mathrm{~kJ} / \mathrm{mol}$ for MG-1 while the peak temperature remains unchanged. A reasonable explanation would be that the grafted PEG chains hinder the phase separation process of NiPAM polymer chains and consequently influence the values of the transition enthalpy. This was shown by Chen et al. by studying four poly(NiPAM) grafted poly(ethylene oxide) of almost the same average molar mass, PNiPAM-g-PEO copolymers, with different NiPAM/PEO molar ratio. They observed that the phase transition enthalpy of the copolymers decreases from $5.6 \mathrm{~kJ} / \mathrm{mol}$ for the higher NiPAM/PEO ratio to 1.7 $\mathrm{kJ} / \mathrm{mol}$ for the copolymers having the lower NiPAM/POE ratio, i.e. the copolymers with the higher PEO content. ${ }^{22}$ On their side, Spevacek et al. also reported that the architecture of the copolymers strongly impacts the phase transition enthalpy of the NiPAM-based copolymers. They demonstrate a sharp decrease of the enthalpy value for diblock copolymers, PEO-bPNiPAM, and Y-shape triblock, PEO-b-(PNiPAM) 2 , compared to NiPAM homopolymers. ${ }^{23}$ Similarly, Lin et al. have shown that the transition enthalpy of copolymers constituted of PEG and PNiPAm is impacted by the copolymers architecture (block or star). ${ }^{24}$ In the present work, we note that the phase transition temperature does not vary with the incorporation of PEG within the microgels. This statement is not consistent with Teodorescu et al. who have 


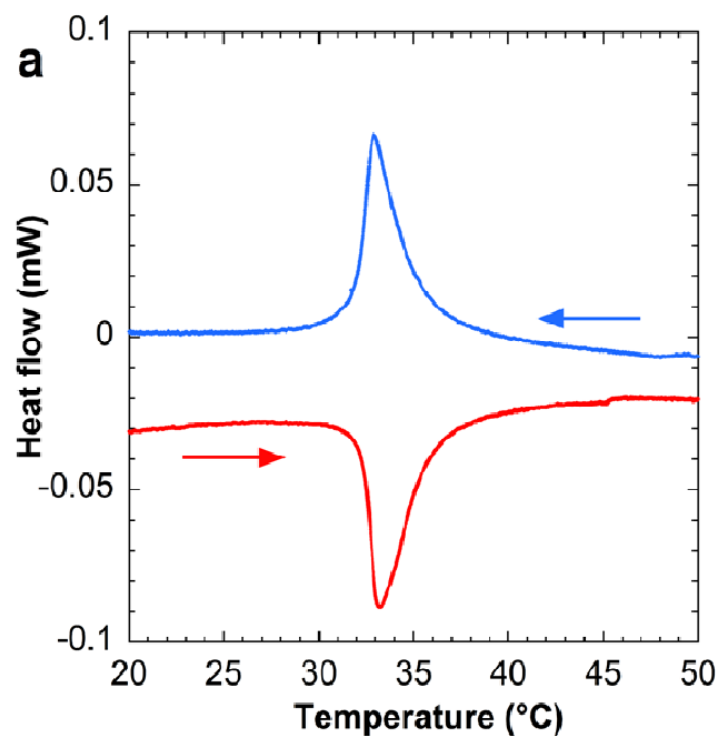

studied the phase transition of PNiPAM- $b$-PEG- $b$-PNiPAM triblock copolymers and observed that the phase transition temperature increases when decreasing the NiPAM to PEG ratio. ${ }^{25,26}$

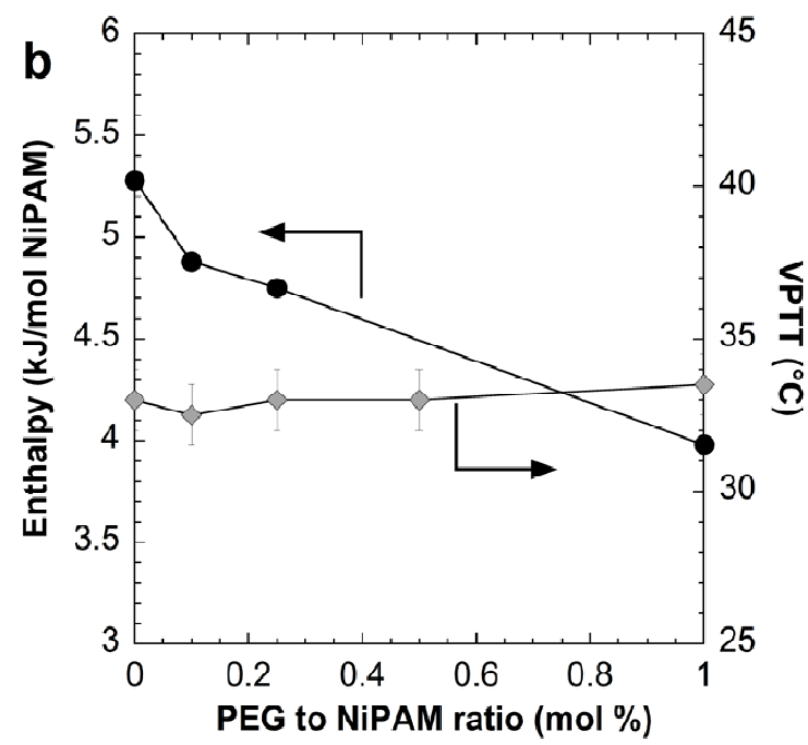

Fig. 2 (a) Thermograms of the MG-1 microgel obtained by $\mu \mathrm{DSC}$ with a microgel concentration $\mathrm{C}_{\mathrm{MG}}=0.5 \mathrm{wt} \%$ at a heating and cooling rate of $0.1{ }^{\circ} \mathrm{C} / \mathrm{min}$. (b) Variation of the enthalpy $(\bullet \mathrm{kJ} / \mathrm{mol} \mathrm{NiPAM})$ and VPTT $(\diamond)$ of PEGylated NiPAM-based microgels as a function of the PEG to NiPAM ratio.

\section{Influence of PEG incorporation on size, size polydispersity and VPTT of microgels}

The temperature dependence of the size of NiPAM-based microgels as a function of the

PEG content was investigated using dynamic light scattering from 10 to $50{ }^{\circ} \mathrm{C}$, i.e., at temperatures well below and above the temperature of the NiPAM phase transition previously determined by calorimetry (Figure 2). Table 2 reports the main characteristics of the 
microgels, namely their size, polydispersity, VPTT and estimated molar masses. Microgels were also characterized by scanning electron microscopy (SEM) (Figure 4). First, we can observe in Figure 3a that both the temperature $\left(33 \pm 1{ }^{\circ} \mathrm{C}\right)$ and sharpness of volume phase transition of NiPAM-based microgels are maintained whatever the amount of incorporated PEG up to 11.7 wt \% (MG1). These results are in contrast with reported studies where the VPTT of NiPAM microgels shifts towards high temperature and becomes broader when increasing the PEG macrocomonomer content in the NiPAM-based microgel due to the hydrophilic character of PEG chains. ${ }^{14,15,27}$ This trend is indeed general as it was also observed in the case of NiPAM microgels copolymerized with hydrophilic comonomers, neutral or charged. ${ }^{12,28,29}$ Also, compared to pure NiPAM microgels (MG-0), PEGylated PNiPAM-based microgels synthesized in the present work are monodisperse irrespective of the PEG content as shown by SEM (Figure 4), in agreement with polydispersity indexes $(\mathrm{PDI}=0.03-0.09)$ obtained by dynamic light scattering (Table 2). Differences (size control and VPTT) between reported studies on PEGylated NiPAM microgels ${ }^{14,} 27$ and our synthesized microgels may be explained by both the polymerization process and the average molar mass of the PEG comonomer. Gan et al. synthesized NiPAM microgels with PEG methacrylate $\left(M_{\mathrm{w}}=1000 \mathrm{~g} / \mathrm{mol}\right)$ by precipitation polymerization using sodium dodecyl sulfate as surfactant. The use of surfactant, which controls the microgel growth, ${ }^{30,} 31$ allows them to maintain a similar microgel size whatever the PEG macromonomer content which does not participate to the microgel stabilization during the growth process. Surfactant precipitation polymerization results to a higher incorporation of PEG into the microgel and consequently changes the behavior in solution of the microgels, i.e. a shift of the VPTT towards high temperature with PEG increasing. On the other hand, Ma et al. have synthesized NiPAM microgels by surfactant free precipitation polymerization using low molar mass PEG methacrylate $\left(M_{\mathrm{n}}=520 \mathrm{~g} / \mathrm{mol}\right)$. The incorporation of the PEG of low molar mass has almost 
no effect on the microgel final size (from $R_{\mathrm{h}}=230$ to $250 \mathrm{~nm}$ ) in spite of the PEG amount used in the synthesis (from 0 to $8 \mathrm{~mol} \%$ respectively). However, this incorporation strongly impacts the VPTT of the microgels which shifts towards high temperature. Finally, the comparison of both the characteristics of the microgels (size, polydispersity) and their thermal behavior (VPTT) between reported studies and the present work is not straightforward. Furthermore, Pich et al. who synthesized poly( $N$-vinyl caprolactam $)$ microgels with a PEG methacrylate similar to the one we have used $\left(M_{\mathrm{w}}=2000 \mathrm{~g} / \mathrm{mol}\right)$ which exhibit a similar behavior concerning the evolution of the size of the microgel as a function of the PEG methacrylate content, i. e., the microgel size decreases as the PEG amount in the synthesis increases. ${ }^{32}$ In our case, the value and the sharpness of the VPTT of the microgels remains unchanged whatever the PEGMAOH introduced in the reaction medium. Based on the reactivity ratios of both monomers reported by Alava et al., this assumes that synthesized microgels exhibit a structure where the NiPAM monomers mainly constitute the core and PEG chains are located on the microgel periphery. Due to this composition, PEG chains do not disrupt the phase transition of PNiPAM chains and consequently the VPTT of the microgels. This hypothesis is supported by the research work of Hoare et al. on the synthesis of NiPAM-based microgels with acid comonomers with different reactivity ratios. More precisely, they observe that the VPTT of microgels do not change when the comonomers, according to the reactivity ratios, are located at the microgel periphery. ${ }^{33}$

Figure $3 \mathbf{b}$ shows that the size of the microgel linearly decreases from a hydrodynamic radius value, $R_{\mathrm{h}}$, around $330 \mathrm{~nm}(\mathrm{MG}-0)$ to $110 \mathrm{~nm}(\mathrm{MG}-1)$ at $25{ }^{\circ} \mathrm{C}$ when increasing PEG molar ratio from 0 to $1 \mathrm{~mol} \%$. The evolution of the microgel size with the PEG macromonomer content can reasonably be explained by considering their polymerization mechanism. It is generally well accepted that microgels grow until they acquire a colloidal stability, which prevents the addition of either free chains or other precursor particles. For the 
pure NiPAM microgel, MG-0, the colloidal stability is only achieved owing to electrostatic repulsions coming from the presence of the charged initiator. In the case of PEGylated NiPAM microgels, the presence of PEG chains, which remain in good solvent at $67{ }^{\circ} \mathrm{C}$ provides microgels with a supplementary stability of steric origin in addition to the electrostatic stabilization due to the initiator. Consequently, the growth of the microgels may stop at an earlier stage. As a result, the higher the PEG ratio, the smaller the microgel size.

The microgel swelling ratios, $Q_{\mathrm{v}}$ defined as the quotient of the hydrodynamic volumes at 25 ${ }^{\circ} \mathrm{C}$ and $45{ }^{\circ} \mathrm{C}$ are reported in Table 2 . We found that the swelling ratios of all the PEG containing microgels are around an average value of 10 whereas the swelling ratio of MG-0 is about 20. For pure NiPAM microgels synthesized by surfactant free precipitation polymerization, it is well-known that microgels exhibit a non uniform morphology induced by a radial distribution of the crosslink points in the microgel network due to the reactivity difference between the crosslinker, MBA, and NiPAM. Indeed, it has been reported that the conversion rate of MBA is faster than NiPAM monomer leading to the presence of PNiPAM dangling chains, formed at the end of the reaction, at the microgel periphery. ${ }^{34,}{ }^{35}$ The presence of the dangling chains, which extend towards the aqueous phase strongly impacts on the hydrodynamic diameter at temperatures below the microgel's VPTT. However, at temperatures higher than VPTT, the collapse of both the PNiPAM dangling chains and microgel core leads to high values of the swelling ratio $Q_{\mathrm{v}}$. In our case, we assume that the rapid incorporation of the PEG chains into the microgel, which stops their growth earlier in the polymerization process, decreases the number of PNiPAM dangling chains at the periphery of the microgel. As a consequence, the difference in size between the swollen and collapsed states of the microgels below and above VPTT is of a lesser importance therefore inducing smaller $Q_{\mathrm{v}}$ swelling ratios. 
We would like to point out that the synthesis of PEGylated microgels is highly reproducible. Indeed, different synthesis batches give microgels with similar sizes and temperature dependences as the size of the symbols represents the microgel size error bars.(Figure S1 in Supporting Information, SI).
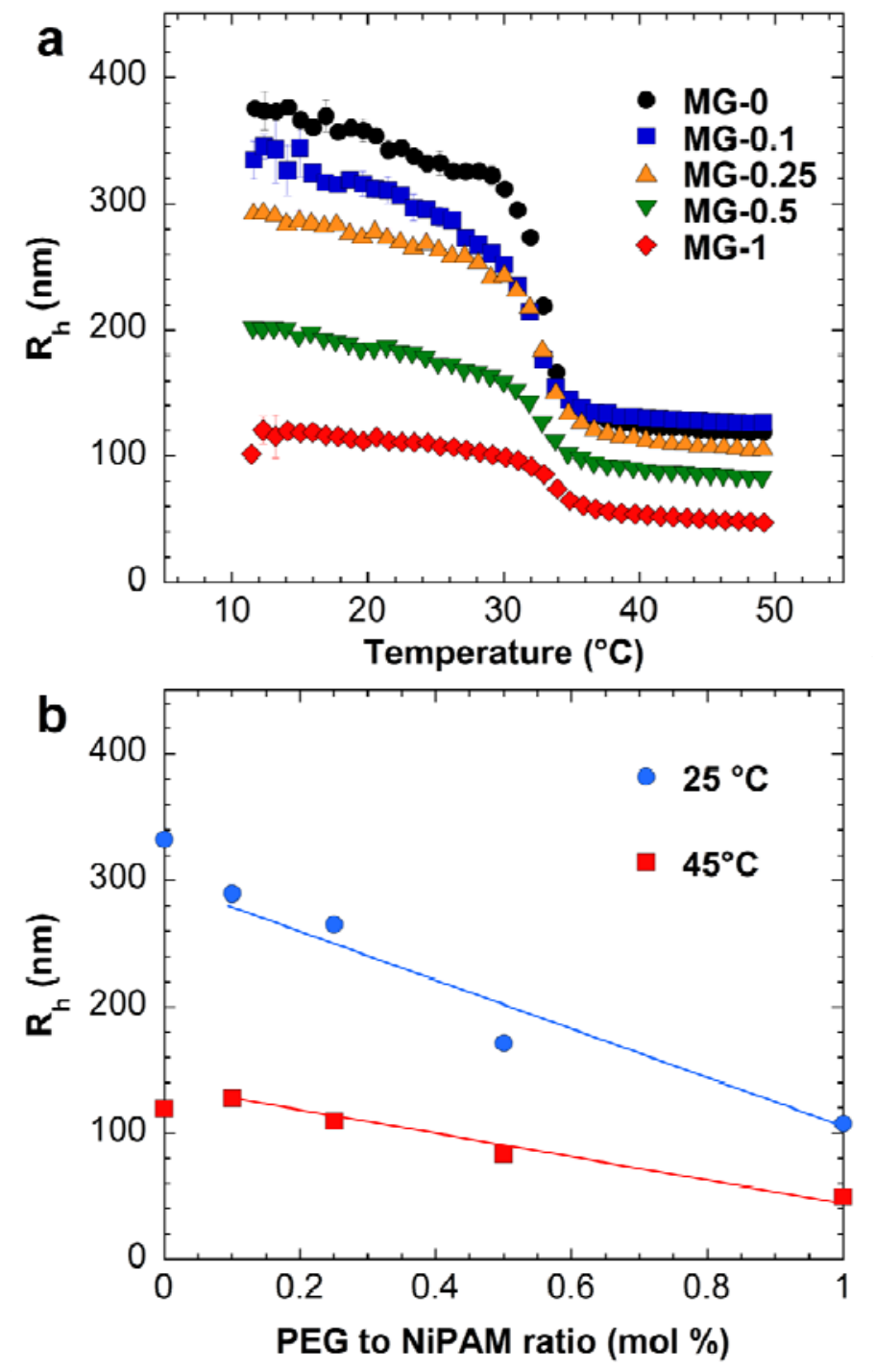

Fig. 3 (a) Hydrodynamic radius, $R_{\mathrm{h}}$, of the PEGylated NiPAM-based microgels as a function of temperature. (b) Hydrodynamic radius, $R_{\mathrm{h}}$, of the PEGylated microgels at 25 and $45^{\circ} \mathrm{C}$ as a function of the molar ratio of PEGMAOH to NiPAM in the batch synthesis. The lines are guides for the eyes. 

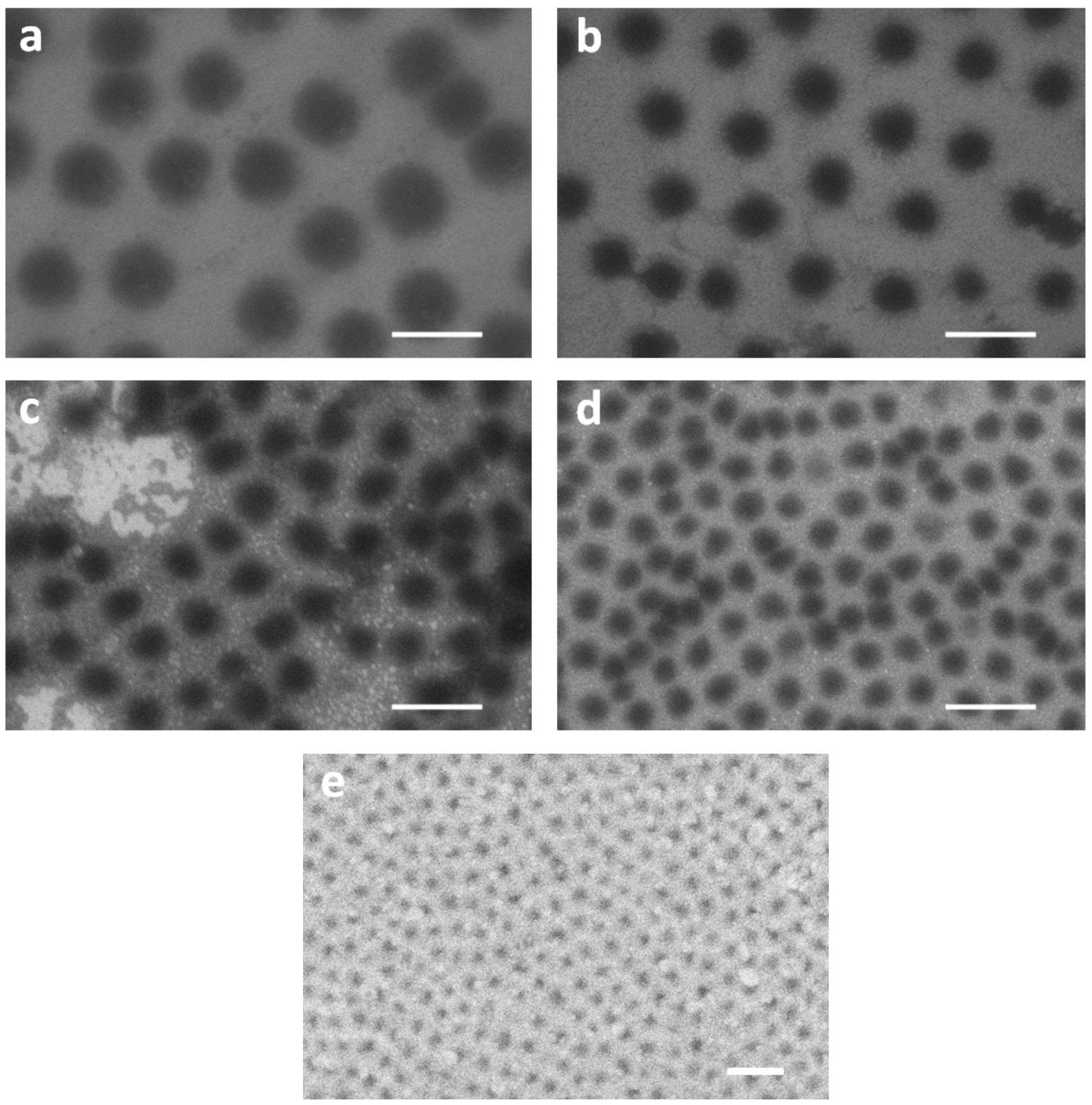

Fig. 4 SEM images of PEGylated microgels (a) MG-0, (b) MG-0.1, (c) MG-0.25, (d) MG-0.5 and (e) MG-1. The scale bar is $1 \mu \mathrm{m}$. 
Table 2 Hydrodynamic radius, polydispersity, swelling ratio, VPTT and estimated molar mass of the synthesized microgels deduced from DLS measurements

\begin{tabular}{|c|c|c|c|c|c|c|c|}
\hline Microgel & $\begin{array}{l}R_{h\left(25^{\circ} \mathrm{C}\right)} \\
\quad(\mathrm{nm})\end{array}$ & $\operatorname{PDI}\left(25^{\circ} \mathrm{C}\right)$ & $\begin{array}{l}R_{h\left(45^{\circ} \mathrm{C}\right)} \\
\quad(\mathrm{nm})\end{array}$ & $P D I\left(45^{\circ} \mathrm{C}\right)$ & $Q_{v}{ }^{a}$ & $\begin{array}{c}V P T T \\
\left({ }^{\circ} \mathrm{C}\right)\end{array}$ & $\begin{array}{c}M_{w} 10^{6} \\
(\mathrm{~g} / \mathrm{mol})^{b}\end{array}$ \\
\hline MG-0 & 332 & 0.22 & 119 & 0.03 & $21 \pm 1$ & 33 & 3435 \\
\hline MG-0.1 & 289 & 0.06 & 127 & 0.01 & $11 \pm 1$ & 33 & 4131 \\
\hline MG-0.25 & 265 & 0.09 & 110 & 0.03 & $14 \pm 1$ & 33 & 2621 \\
\hline MG-0.5 & 171 & 0.03 & 83 & 0.02 & $9 \pm 1$ & 33 & 1163 \\
\hline MG-1 & 107 & 0.08 & 49 & 0.02 & $10 \pm 1$ & 33 & 242 \\
\hline
\end{tabular}

\section{Influence of PEG incorporation on the colloidal stability of NiPAM-based microgels}

As discussed in the introduction, the colloidal stability of stimuli-responsive microgels is crucial for their use in many applications. In order to investigate the influence of the PEG chains incorporation on the colloidal stability of PEGylated NiPAM-based microgels, we studied the macroscopic stability diagrams and measured the zeta potential of the microgels. The results are shown in Figures 5 and 6. The temperature dependence of the zeta potential,

$352 \zeta$, for all synthesized microgels is characteristic of the general trend of thermoresponsive 353 NiPAM-based microgels synthesized using an anionic initiator. ${ }^{36}$ First, at low temperature microgels exhibit a low value of zeta potential coming from the dispersion of charges onto the large microgel surface. Then, the absolute value of zeta potential rapidly increases above the 
VPTT of the microgels, as the microgel collapses. As shown in Figure 5, we observe a clear dependence of the zeta potential above the VPTT as PEG chains are incorporated into the microgel. For instance, the absolute value of zeta potential decreases at $45^{\circ} \mathrm{C}$ from $\zeta=-48 \mathrm{mV}$ for pure NiPAM microgel (MG-0) to $\zeta=-16 \mathrm{mV}$ for microgel synthesized with $1 \mathrm{~mol} \%$ of PEG (MG-1). This feature may also be rationalized by considering the polymerization mechanism of the microgels in the presence of PEG macro-comonomers. As already discussed above, PEG chains provide additional stability during the polymerization process and allow to stop earlier the growth of the microgel. As a consequence, we suggest that the number of anionic sulfate groups within the microgel coming from the initiator decreases with increasing the amount of PEG chains. This is coherent with the observed increase of the zeta potential values for PEGylated microgels containing larger amount of PEG as temperature exceeds VPTT.

However, a small amount of charges at the microgel surface is unfavorable to colloidal stability, notably in the presence of electrolytes, which limits the range of applications. In order to investigate the colloidal behavior of the microgels in aqueous solution, stability diagrams were determined at various temperatures in the presence of a divalent salt $\left(\mathrm{CaCl}_{2}\right)$. The results are shown in Figure 6 and Figure S2 in Supporting Information. It is widely reported in the literature that the presence of electrolyte in microgel dispersions leads to a temperature-induced flocculation characterized by a critical flocculation temperature. ${ }^{8,10,36,37}$ These reports converge to the fact that the higher the electrolyte concentration, the lower the critical flocculation temperature. This general trend is verified in our case for pure NiPAM microgel (MG-0) in the presence of calcium chloride with an aggregation of the microgels observed from $0.01 \mathrm{M}$ in $\mathrm{CaCl}_{2}$ starting at $35{ }^{\circ} \mathrm{C}$ (Figure 6a) We also observed that the critical flocculation temperature decreases when increasing the salt concentration. ${ }^{8}$ Remarkably, microgels synthesized with 1 mol \% of PEG macro-comonomer (MG-1) are 


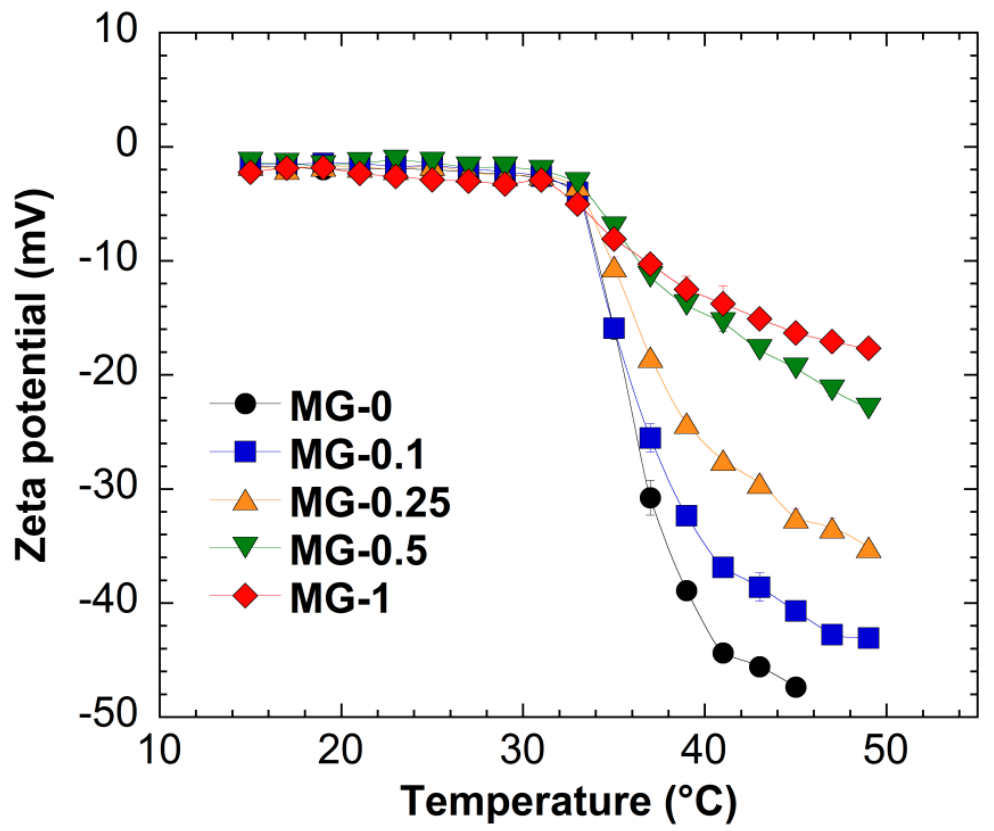

Fig. 5 Zeta potential as a function of the temperature for PEGylated microgel dispersions at a microgel concentration $\mathrm{C}_{\mathrm{MG}}=0.1 \mathrm{wt} \%$ in aqueous $10^{-4} \mathrm{M} \mathrm{NaCl}$. The lines are guides to the eye. 

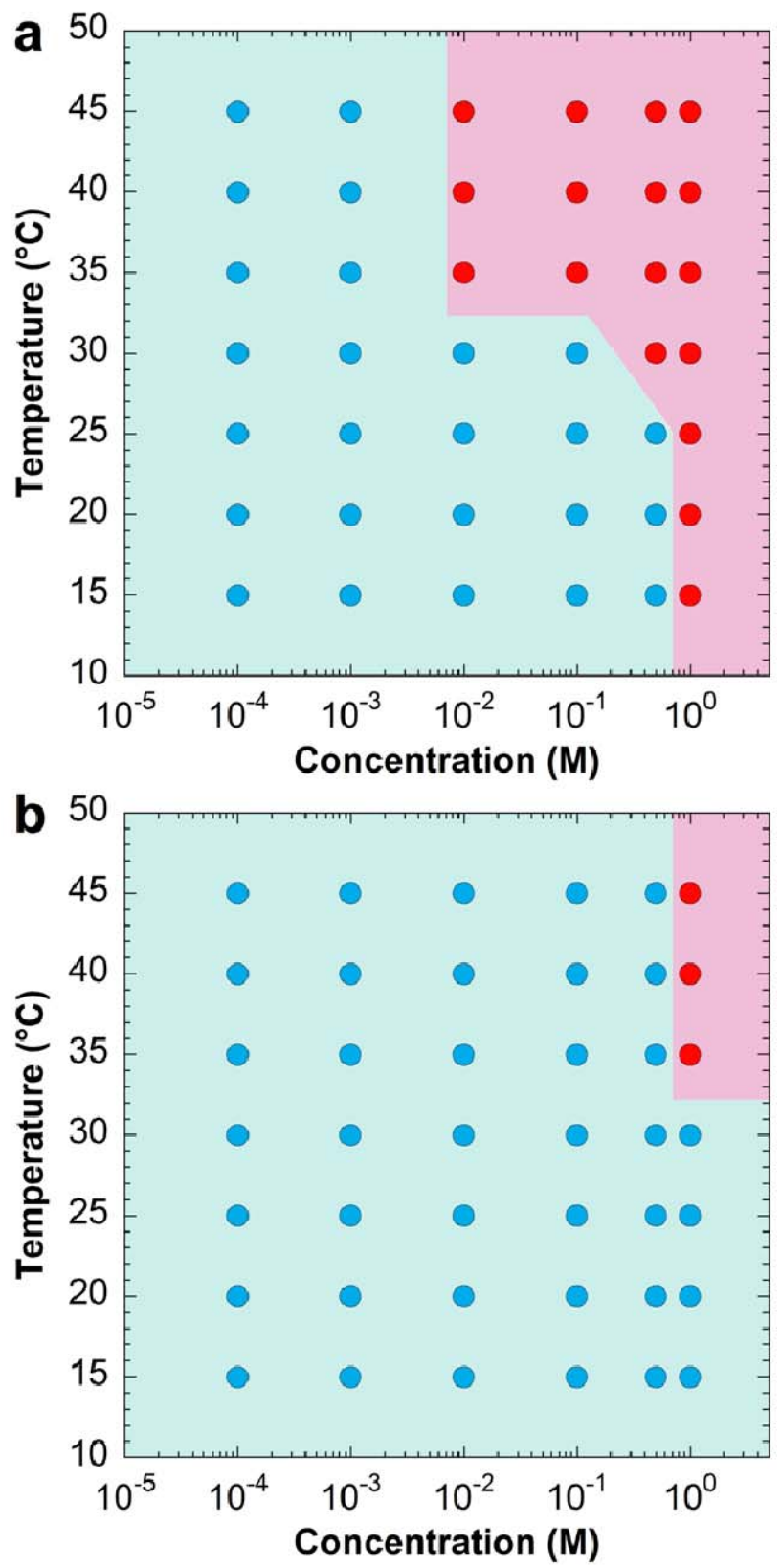

Fig. 6 Macroscopic stability diagrams of solutions of microgels (a) MG-0 and (b) MG-1, as a function of both the temperature and $\mathrm{CaCl}_{2}$ concentration. The microgel concentration is $\mathrm{C}_{\mathrm{MG}}$ $=0.1 \mathrm{wt} \%$. The blue and red colors correspond to one and two phases respectively. 


\section{Localization of the PEG chains in the microgel network}

392

393

The evolution of the ${ }^{1} \mathrm{H}$ NMR spectrum obtained for MG-1 in $\mathrm{D}_{2} \mathrm{O}$ was monitored using isothermal steps during a heating ramp from 2 to $59{ }^{\circ} \mathrm{C}$, as described earlier in the Experimental Section. Figure 7a shows the spectra recorded below and above the PNiPAM VPTT. As expected, above the VPTT, the peaks related to the NiPAM units display a significant broadening, resulting from the reduction of the segmental mobility along the copolymer chains induced by the microgel contraction. Therefore, the signals from the protons of the copolymer backbone $\left(\mathrm{CH}_{2}\right.$ and $\left.\mathrm{CH}\right)$ and the methine proton of isopropyl group $\left(\mathrm{CH}\left(\mathrm{CH}_{3}\right)_{2}\right)$ are not detected any longer. The peak corresponding to the $\mathrm{NiPAM} \mathrm{CH}_{3}$ groups, though broadened, is still observed, owing to their fast internal rotation around the $\mathrm{C}_{3}$ axis. Interestingly, above the VPTT, the peak related to the protons from the PEG side chains still displays a relatively narrow contribution (about $5 \mathrm{~Hz}$ at $53{ }^{\circ} \mathrm{C}$ ). This result indicates that at least part of the PEG repeat units (EG) is mobile enough to be observed, despite the microgel collapse. Here, and in the following, the term "mobile" (or, respectively, "immobile" / "frozen") refers to the segmental dynamics, probed over the tens of microseconds time scale. In order to determine whether at least a fraction of the EG units gets frozen or not during the heating ramp, the fraction of mobile EG units $\left(f_{\mathrm{EG}}\right)$ was measured as a function of temperature, as shown in Figure $7 \mathbf{b}$. The fraction of mobile NiPAM units $\left(f_{\mathrm{NiPAM}}\right)$ was also included, for the sake of comparison. $f_{\mathrm{NiPAM}}$ was derived by considering the peak related to the methine proton of the NiPAM isopropyl groups. Similar results were obtained using the peak assigned to the protons of the NiPAM methyl groups (Figure S3, Supporting Information). As expected, a significant and sharp decrease of $f_{\mathrm{NiPAM}}$ is observed above $38^{\circ} \mathrm{C}$ and less than $7 \%$ of the NiPAM units are detected then. These latter may partly correspond to lowmolecular-weight species. ${ }^{38}$ The sharpness of the temperature evolution of $f_{\mathrm{NiPAM}}$ is in 
agreement with the sharpness of $R_{\mathrm{h}}(T)$, reported in Figure 3a. As far as the PEG side chains are concerned, the NMR experiments show that despite a concomitant decrease of $f_{\mathrm{EG}}$ above the VPTT, the fraction of the remaining mobile EG units is found to be quite significant, about $80 \%$ for MG-1 for instance. This result indicates that only a relatively weak fraction of the EG units gets strongly slowed-down above the VPTT.
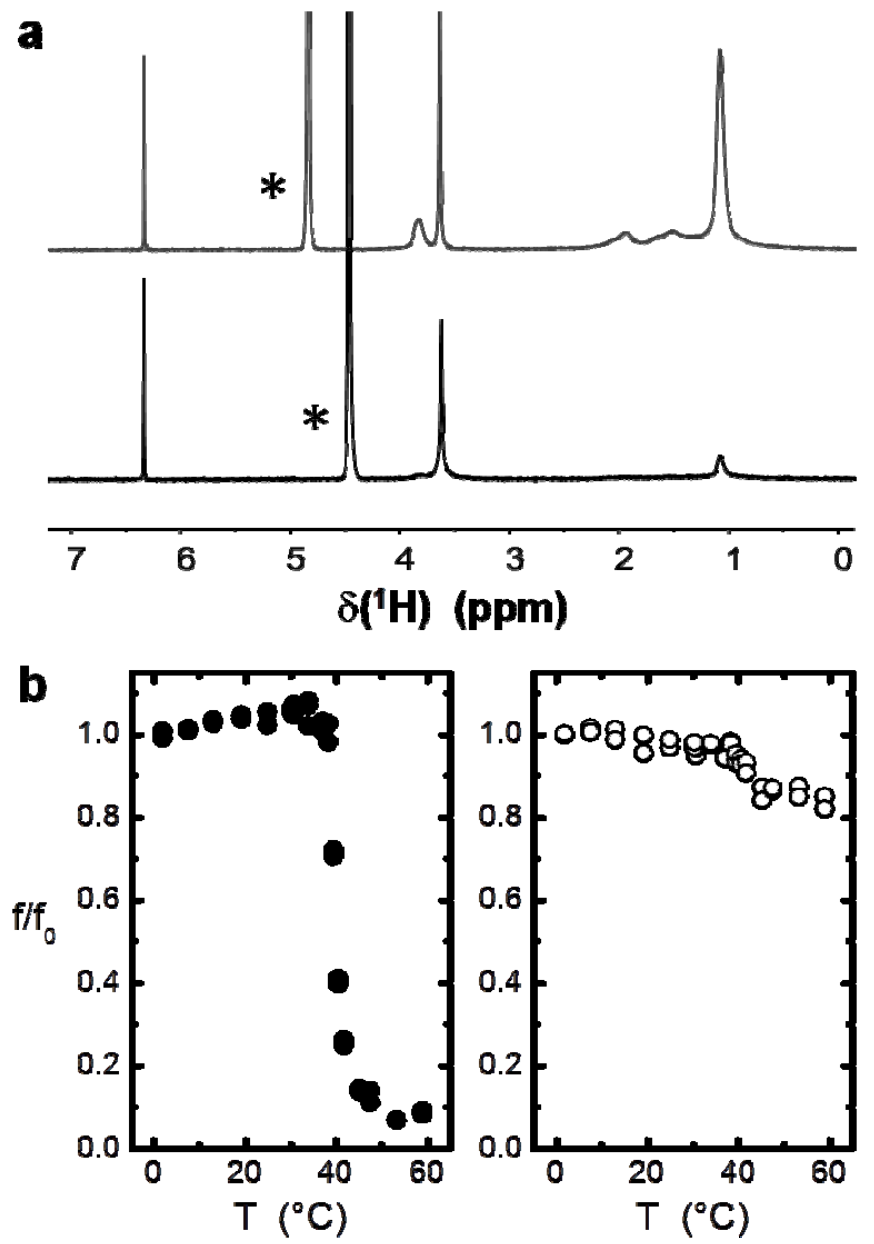

Fig. 7 (a) ${ }^{1} \mathrm{H}$ NMR spectra of MG-1 in $\mathrm{D}_{2} \mathrm{O}$ at 19 and $53{ }^{\circ} \mathrm{C}$, respectively. The microgel concentration $\mathrm{C}_{\mathrm{MG}}$ amounts to $0.05 \mathrm{wt} \%$. The asterisk denotes the peak related to the residual protons of $\mathrm{D}_{2} \mathrm{O}$ whereas the peak at $6.3 \mathrm{ppm}$ corresponds to the $\mathrm{CH}$ protons of maleic acid. (b) Temperature dependence of the fraction $f$ of mobile NiPAM (O) and EG (O) units for MG-1 in $\mathrm{D}_{2} \mathrm{O}$. $f_{0}$ stands for the value of $f$ at the lowest temperature considered (about $2^{\circ} \mathrm{C}$ ). 
The NMR measurements indicate that above the microgel VPTT, the segmental motions of

422 part of the PEG units remain fast over the tens of microseconds time scale. In this temperature

423

424

425 range, the preferential NiPAM/NiPAM interactions lead to the formation of hydrophobic phase-separated NiPAM-rich globules and the hydrophilic PEG chains should tend to be preferentially located out of the globules, that is to say at the outer part of the microgel particles. From a dynamical point of view, such chains should experience a gradient of the segmental mobility, with a progressive release of the local constraint from the external part of the NiPAM-rich core toward the free end of the PEG chain. Figure 8 depicts the ${ }^{1} \mathrm{H}$ transverse relaxation signal determined for the EG units of $\mathrm{MG}-0.5$, at $53{ }^{\circ} \mathrm{C}$, that is to say above the VPTT. In contrast to the situation observed below the VPTT (Figure S4, Supporting Information), a clear deviation from a mono-exponential behavior is indeed observed, which evidences the occurrence of a distribution of the segmental mobility along the PEG chains. From a phenomenological point of view, this relaxation function may be described using the sum of two exponential components, $A_{\mathrm{s}} \times \exp \left(-\mathrm{t} / T_{2 \mathrm{~s}}\right)+A_{\mathrm{L}} \times \exp \left(-\mathrm{t} / T_{2 \mathrm{~L}}\right)$, with $A_{\mathrm{S}}=66 \%\left(A_{\mathrm{L}}=33 \%\right), T_{2 \mathrm{~S}}=70 \mathrm{~ms}$ and $T_{2 \mathrm{~L}}=780 \mathrm{~ms}$. The fast relaxing component may be assigned to the EG units displaying constrained segmental motions, due to the proximity with the NiPAM-rich globules, whereas the long relaxation component should correspond to the units located further from the core. At this stage, it should be noted that such a two-phase model is a rough description of the continuous distribution of the local constraint occurring along the PEG side chains. 


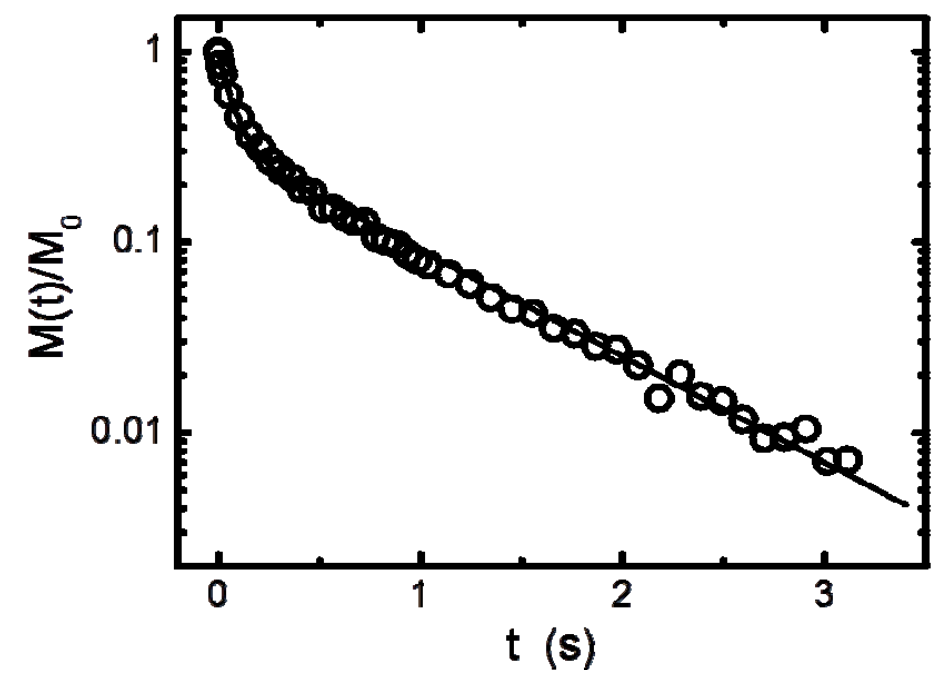

Fig. $8{ }^{1} \mathrm{H}$ transverse relaxation signal $M(t)$ for the protons of the PEG side chains of MG0.5 in $\mathrm{D}_{2} \mathrm{O}\left(\mathrm{C}_{\mathrm{MG}}=0.05 \mathrm{wt} \%\right)$, determined at $53{ }^{\circ} \mathrm{C}$. The solid line stands for the fit of the experimental data using the sum of two exponential relaxation components.

The segmental dynamics of the PEG chains within the shell surrounding the NiPAM-rich globules should be somehow similar to the behavior of PEG chains in block copolymer micelles formed in water. One may thus compare our NMR data to the ones reported by de Graaf et al. for PNiPAM- $b$-PEG diblock copolymers, with a similar molar mass for the PEG chains (about $2000 \mathrm{~g} / \mathrm{mol}) .{ }^{39}$ In this reference, the ${ }^{1} \mathrm{H}$ NMR transverse relaxation signal of the PEG chains in the PNiPAM- $b$-PEG diblock micelles was reported above the VPT. The data could also be described using two $T_{2}\left({ }^{1} \mathrm{H}\right)$ relaxation components and the corresponding relaxation time values, $T_{2 \mathrm{~S}}$ and $T_{2 \mathrm{~L}}$, were found to be close to $60 \mathrm{~ms}$ and $1000 \mathrm{~ms}$, respectively, at $45{ }^{\circ} \mathrm{C}$ and at a ${ }^{1} \mathrm{H}$ Larmor frequency of $500 \mathrm{MHz}$. These $T_{2}\left({ }^{1} \mathrm{H}\right)$ values stand in the same order of magnitude as the ones determined on MG-0.5 (70 and $780 \mathrm{~ms})$. Such a similarity provides an additional support to the assignment of the fraction of mobile EG units detected above the VPTT on the ${ }^{1} \mathrm{H}$ NMR spectra (Figure 7a). Such chains should mostly correspond to dangling chains at the periphery of the NiPAM-rich globules. 
Let us now consider the remaining fraction of the EG units in the microgels, the one that becomes immobilized above the VPTT (Figure 7b). It may be worth remarking that such frozen-like units were not detected for micelles of PNiPAM-b-PEG diblock copolymers. Although the localization of the PEG chains at the surface of the microgel particles should be favored from an enthalpic point of view, some PEG chains or PEG chain portions could nevertheless be entrapped within the NiPAM globules. Indeed, as the VPTT occurs, the PEG chains should diffuse toward the external part of the microgel particles. However, in contrast to the case of diblock copolymers, one copolymer chain contains several PEG side chains about 12 for MG-1 for instance - so that the migration of all the PEG chains toward the periphery would require a significant reorganization of the conformation displayed by the copolymer chains involved within the microgel particles. Besides, during the VPTT, most of the water molecules are expelled from the NiPAM-rich globules and therefore, the reorientational motions of the NiPAM units undergo a significant slowing-down over the tens of microseconds time scale, as evidenced in Figure 7a. As a result, the diffusion of the PEG side chains within the forming NiPAM-rich globules is expected to become considerably slower. Under this context, part of the PEG units should remain embedded within the NiPAM-rich cores.

The NMR results derived for MG-1 were compared to the ones derived from the other microgels, characterized by a varying fraction of PEG chains. In any cases (Figure S5, Supporting Information), a similar trend is observed for $f_{\mathrm{PEG}}(T)$. The onset of the VPTT occurs at the same temperature (around $38{ }^{\circ} \mathrm{C}$ ) and the transition extends over a similar temperature range (from 38 to $45-47^{\circ} \mathrm{C}$ ). In contrast, as shown in Figure 9, the fraction of the EG units that becomes frozen over the VPTT decreases from 66 to $15 \%$ as the PEG content within the microgel is raised up from 0.10 to $1 \mathrm{~mol} \%$. Such an evolution is in qualitative agreement with the assignment proposed for the fraction of EG units immobilized during the 
volume phase transition. Indeed, the increase of the proportion of PEG side chains

482 incorporated along the copolymer chains was found to result in a smaller size of the microgel

483

484

485

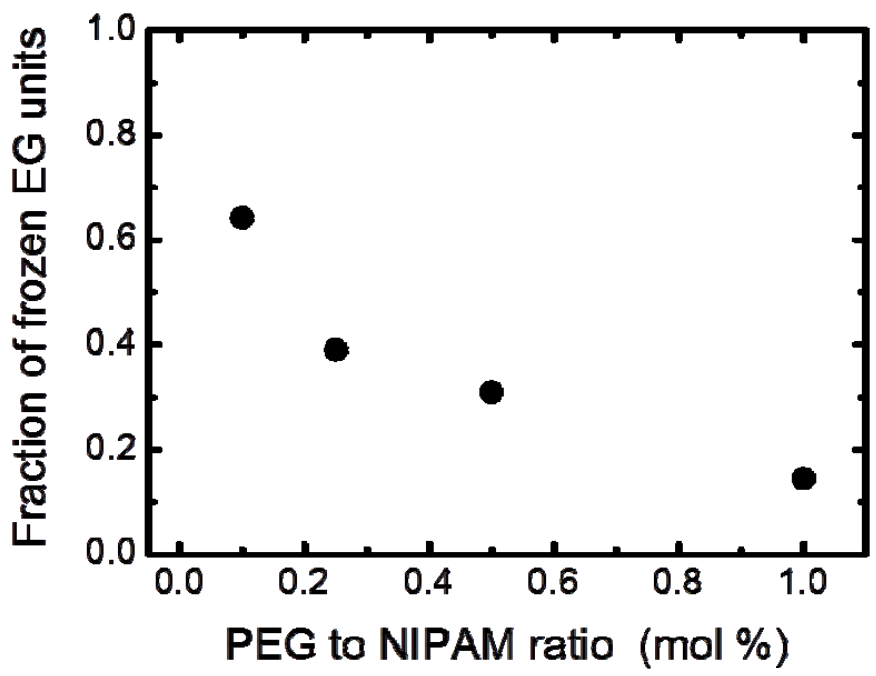

Fig. 9 Evolution of the fraction of EG units that becomes immobile, over the tens of microseconds time scale, during the volume phase separation process of the microgels, with the PEG to NiPAM molar ratio used for the microgel synthesis. 
499

500

501

502

503

504

505

506

507

508

509

510

511

512

513

514

515

516

517

518

519

520

In the present work, we have demonstrated the possibility to easily synthesize monodisperse PEGylated NiPAM-based microgels by surfactant-free precipitation polymerization. We have shown that (i) the incorporation of PEG chains into the microgel synthesis allows to precise control of the size and dispersity of the microgels (ii) despite the incorporation of hydrophilic PEG chains, the synthesized microgels maintain a sharp VPTT similar to pure NiPAM microgels thanks to the reactivity ratios of NiPAM and PEGMAOH monomers leading a microgel structure in which PEG chains are located at the microgel periphery as clearly shown by detailed NMR study (iii) the presence of PEG chains allows to improve the colloidal stability of the microgels in electrolyte solutions even at high temperature. Finally, the presence of a hydroxyl group located at the end of PEG chains allows to envisage a possible post-functionalization.

\section{CONFLICTS ON INTEREST}

There are no conflicts to declare

\section{ACKNOWLEDGMENTS}

We gratefully acknowledge the financial support of CNRS, ESPCI, and the Ph.D. school of Sorbonne Université (ED 397, Sorbonne Université) for the Ph.D. fellowship funding of J. Es Sayed. The authors thank Bruno Bresson from SIMM for technical advice on scanning electron microscopy. The authors gratefully acknowledge Nadège Pantoustier for fruitful discussion. 
522

5231 S. Nayak and L. A. Lyon, Angewandte Chemie-International Edition, 2005, 44, 7686-7708.

5242 A. V. Kabanov and S. V. Vinogradov, Angewandte Chemie-International Edition, 2009, 48, $525 \quad 5418-5429$.

5263 J. K. Oh, R. Drumright, D. J. Siegwart and K. Matyjaszewski, Progress in Polymer Science, $5272008,33,448-477$.

5284 A. E. Ekkelenkamp, M. R. Elzes, J. F. J. Engbersen and J. M. J. Paulusse, Journal of Materials 529 Chemistry B, 2018, 6, 210-235.

5305 C. D. Sorrell and M. J. Serpe, Anal. Bioanal. Chem., 2012, 402, 2385-2393.

5316 F. A. Plamper and W. Richtering, Accounts of Chemical Research, 2017, 50, 131-140.

5327 R. Pelton, Advances in Colloid and Interface Science, 2000, 85, 1-33.

5338 E. Daly and B. R. Saunders, Langmuir, 2000, 16, 5546-5552.

5349 R. H. Pelton and P. Chibante, Colloids and Surfaces, 1986, 20, 247-256.

53510 M. J. Snowden and B. Vincent, Journal of the Chemical Society, Chemical Communications, $5361992,1103-1105$.

53711 Z. H. Farooqi, H. U. Khan, S. M. Shah and M. Siddiq, Arabian Journal of Chemistry, 2017, $538 \quad 10,329-335$.

53912 M. Das, N. Sanson and E. Kumacheva, Chemistry of Materials, 2008, 20, 7157-7163.

54013 J. S. Suk, Q. Xu, N. Kim, J. Hanes and L. M. Ensign, Advanced Drug Delivery Reviews, 2016, $54199,28-51$.

54214 D. Gan and L. A. Lyon, Macromolecules, 2002, 35, 9634-9639.

54315 T. Trongsatitkul and B. M. Budhlall, Colloids and Surfaces B-Biointerfaces, 2013, 103, 244544252.

$54516 \quad$ N. Sanson and J. Rieger, Polymer Chemistry, 2010, 1, 965-977.

54617 J. A. Aguilar, M. Nilsson, G. Bodenhausen and G. A. Morris, Chemical Communications, $547 \quad 2012,48,811-813$. 

Aspects, 2005, 270-271, 18-25.

55019 H. G. Schild, Progress in Polymer Science, 1992, 17, 163-249.

$55120 \quad$ K. Otake, H. Inomata, M. Konno and S. Saito, Macromolecules, 1990, 23, 283-289.

55221 H. G. Schild and D. A. Tirrell, The Journal of Physical Chemistry, 1990, 94, 4352-4356.

55322 H. Chen, Q. Zhang, J. Li, Y. Ding, G. Zhang and C. Wu, Macromolecules, 2005, 38, 8045-

5548050.

55523 J. Spevacek, R. Konefal, J. Dybal, E. Cadova and J. Kovarova, European Polymer Journal, $5562017,94,471-483$.

$55724 \quad$ H.-H. Lin and Y.-L. Cheng, Macromolecules, 2001, 34, 3710-3715.

55825 M. Teodorescu, I. Negru, P. O. Stanescu, C. Draghici, A. Lungu and A. Sarbu, Reactive \& $559 \quad$ Functional Polymers, 2010, 70, 790-797.

56026 M. Teodorescu, I. Negru, P. O. Stanescu, C. Draghici, A. Lungu and A. Sarbu, Journal of 561 Macromolecular Science Part a-Pure and Applied Chemistry, 2011, 48, 177-185.

56227 X. Ma, J. Xi, X. Zhao and X. Tang, Journal of polymer science part b: polymer physics, 2005, $56343,3575-3583$.

56428 A. Burmistrova, M. Richter, M. Eisele, C. Üzüm and R. von Klitzing, Polymers, 2011, 3, 5651575.

56629 M. J. Snowden, B. Z. Chowdhry, B. Vincent and G. E. Morris, Journal of the Chemical 567 Society, Faraday Transactions, 1996, 92, 5013-5016.

56830 W. McPhee, K. C. Tam and R. Pelton, Journal of Colloid and Interface Science, 1993, 156, $569 \quad 24-30$.

$57031 \quad$ B. Wedel, T. Brändel, J. Bookhold and T. Hellweg, ACS Omega, 2017, 2, 84-90.

57132 A. Pich, S. Berger, O. Ornatsky, V. Baranov and M. A. Winnik, Colloid and Polymer Science, $572 \quad 2009,287,269-275$.

$573 \quad 33$ T. Hoare and R. Pelton, Current Opinion in Colloid \& Interface Science, 2008, 13, 413-428.

57434 M. Stieger, W. Richtering, J. S. Pedersen and P. Lindner, Journal of Chemical Physics, 2004, $575120,6197-6206$. 
57635 X. Wu, R. H. Pelton, A. E. Hamielec, D. R. Woods and W. McPhee, Colloid and Polymer 577 Science, 1994, 272, 467-477.

$57836 \quad$ R. H. Pelton, H. M. Pelton, A. Morphesis and R. L. Rowell, Langmuir, 1989, 5, 816-818.

57937 A. F. Routh and B. Vincent, Langmuir, 2002, 18, 5366-5369.

$58038 \quad$ J. Spevacek, L. Hanykova and L. Starovoytova, Macromolecules, 2004, 37, 7710-7718.

58139 A. J. de Graaf, K. W. M. Boere, J. Kemmink, R. G. Fokkink, C. F. van Nostrum, D. T. S.

582 Rijkers, J. van der Gucht, H. Wienk, M. Baldus, E. Mastrobattista, T. Vermonden and W. E. Hennink, 583 Langmuir, 2011, 27, 9843-9848. 